\title{
Coherent Detection of Wavelength Division Multiplexed Phase-Modulated Radio-over- Fibre Signals
}

Zibar, Darko; Yu, Xianbin; Peucheret, Christophe; Jeppesen, Palle; Tafur Monroy, Idelfonso

Published in:

European Conference on Optical Communication

Link to article, DOI:

10.1109/ECOC.2008.4729222

Publication date:

2008

Document Version

Publisher's PDF, also known as Version of record

Link back to DTU Orbit

Citation (APA):

Zibar, D., Yu, X., Peucheret, C., Jeppesen, P., \& Tafur Monroy, I. (2008). Coherent Detection of Wavelength Division Multiplexed Phase-Modulated Radio-over-Fibre Signals. In European Conference on Optical Communication: ECOC 08 (pp. 1-2). IEEE. https://doi.org/10.1109/ECOC.2008.4729222

\section{General rights}

Copyright and moral rights for the publications made accessible in the public portal are retained by the authors and/or other copyright owners and it is a condition of accessing publications that users recognise and abide by the legal requirements associated with these rights.

- Users may download and print one copy of any publication from the public portal for the purpose of private study or research.

- You may not further distribute the material or use it for any profit-making activity or commercial gain

- You may freely distribute the URL identifying the publication in the public portal 


\title{
Coherent Detection of Wavelength Division Multiplexed Phase- Modulated Radio-over-Fibre Signals
}

\author{
D. Zibar, X. Yu, C. Peucheret, P. Jeppesen and I. Tafur Monroy \\ Department of Photonics Engineering, Technical University of Denmark, DK-2800 Kgs. Lyngby, Denmark, \\ email: $\underline{d z @ c o m . d t u . d k}$
}

\begin{abstract}
A WDM phase-modulated Radio-over-Fibre link using digital coherent detection is experimentally demonstrated. $3 \times 50 \mathrm{Mb} / \mathrm{s}$ WDM transmission of a BPSK modulated $5 \mathrm{GHz}$ RF carrier is achieved over $25 \mathrm{~km}$.
\end{abstract}

\section{Introduction}

Radio-over-Fibre systems employing WavelengthDivision-Multiplexing (WDM) are very attractive since they can support a large number of antenna base stations connected to a central station [1]. It is believed that WDM RoF technology can potentially enable increased overall capacity, low-cost antenna base station implementation, increased wireless access coverage and easier network maintenance $[1,2]$. Recently, phase-modulated RoF optical links have attracted large attention due to their advantages compared to intensity modulation [3,4]. However, phase-modulated optical links require a linear coherent receiver. The advantage of linear coherent receivers is not only that they can provide linear $R F$ signal transport, but can also act like ultra-narrow tunable WDM filters. A combination of WDM and phase-modulation could therefore potentially provide large capacity linear RF systems. In this paper, we report on the successful demonstration of $3 \times 50 \mathrm{Mb} / \mathrm{s}$ BPSK WDM phase-modulated RoF link ( $5 \mathrm{GHz}$ RF carrier) over $25 \mathrm{~km}$ of SMF, using digital coherent detection. We demonstrate signal demodulation and subsequent data recovery for WDM channel spacings of $25 \mathrm{GHz}$ and $12.5 \mathrm{GHz}$. To the best of our knowledge, this the first transmission experiment of a WDM phase-modulated RoF link, with BPSK modulation format, and using a digital coherent receiver for simultaneous detection and demultiplexing.

\section{Experimental set-up}

The experimental set-up for the WDM phase modulated radio-over-fibre optical link is shown in Fig. 1. The transmitter consists of 3 tunable DFB lasers with $2 \mathrm{MHz}$ linewidth and wavelengths in the range between 1550.20 and $1550.60 \mathrm{~nm}$. The output of the transmitter is amplified by a high-power EDFA. A Vector Signal Generator (VSG) is used to generate a RF carrier $(5 \mathrm{GHz})$ which is modulated by a $50 \mathrm{Mb} / \mathrm{s}$ BPSK data signal. The RF data signal is then used to drive a conventional lithium-niobate optical phase modulator. The phase modulated optical data signal is sent through $25 \mathrm{~km}$ of SMF and split in two polarizations using a PBS. Only one polarization is sent to the receiver. At the receiver, a 90 optical hybrid is used to mix the received data signal with the tunable external cavity LO laser ( $100 \mathrm{kHz}$ linewidth). The in-phase $\left(\mathrm{I}_{\mathrm{i}}\right)$ and quadrature $\left(\mathrm{I}_{\mathrm{q}}\right)$ optical signal components are detected with two pairs of balanced photodiodes (BW 7.5 GHz).

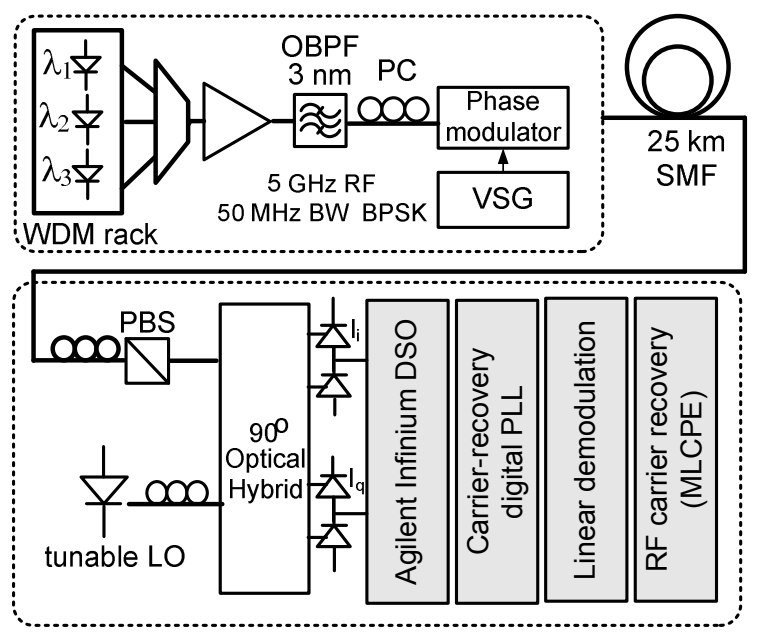

Figure 1. Experimental set-up for the demonstration of WDM phase-modulated RoF optical link.

The wavelength of the LO laser is tunable in order to demultiplex different WDM channels. The detected photocurrents are digitalized at a sample rate of $40 \mathrm{Gs} / \mathrm{s}$ using a high-bandwidth real time oscilloscope (Agilent Infinium DSO80000B with $13 \mathrm{GHz}$ analog bandwidth). The sampled photocurrent is later used for offline signal demodulation and data recovery. The frequency difference between the transmitter and LO laser is measured to be in the range between $20 \mathrm{MHz}$ and $400 \mathrm{MHz}$, depending on the received channel. The post-processing of the digitized data consist of a carrier-recovery digital PLL, linear signal demodulation and an RF carrier phase recovery stage, (see [4] for more details). The carrier-recovery digital PLL is used to remove the frequency and phase offset from the sampled data signal. RF carrier phase recovery is based on the maximum-likelihood approach and the recovered RF carrier is used to demodulate and thereby recover the data.

\section{Experimental results}

Fig 2 shows the optical spectra of the WDM phasemodulated RoF optical signal when the WDM channel 
spacing is $25 \mathrm{GHz}$ and $12.5 \mathrm{GHz}$, respectively. As the WDM channel spacing is reduced to $12.5 \mathrm{GHz}$, significant overlap among channels is observed, making the signal recovery very challenging.

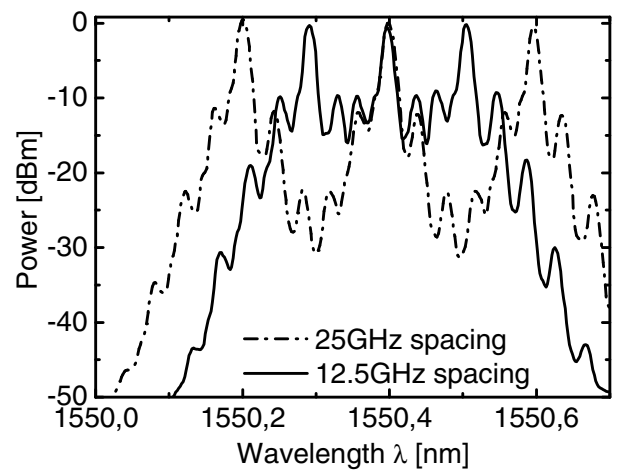

Figure 2. Measured optical spectra of WDM phasemodulated RoF optical signal

To begin with, the WDM channel spacing is set to $12.5 \mathrm{GHz}$. In Fig 3, the Q-factor of the demodulated WDM channel at ${ }_{2}=1550.40 \mathrm{~nm}$ is shown as a function of average received optical power. Results are only provided for the centre channel at 2 since it is the one that experiences most crosstalk from the two neighbouring channels Three different scenarios are considered: 1) two neighbouring WDM channels at ${ }_{1}=1550.20 \mathrm{~nm}$ and ${ }_{3}=1550.60 \mathrm{~nm}$ are present, 2) the WDM channel at ${ }_{1}=1550.20 \mathrm{~nm}$ is removed, and 3) the WDM channels at ${ }_{1}=1550.20 \mathrm{~nm}$ and ${ }_{3}=1550.60 \mathrm{~nm}$ are both removed.

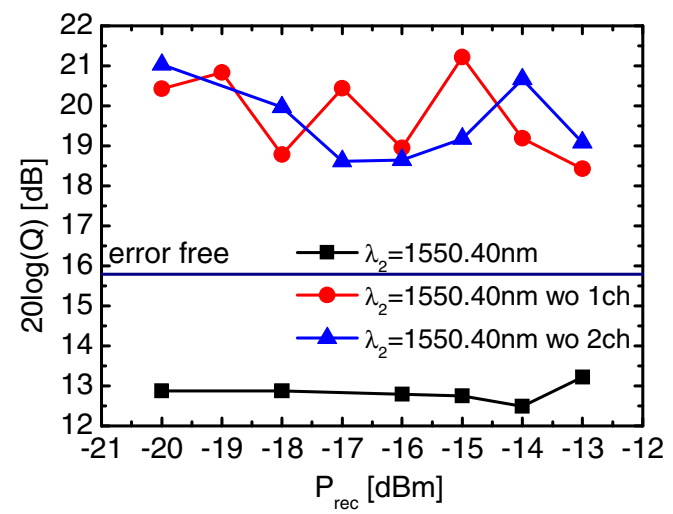

Figure 3. Q-factor of the demodulated WDM channel ( $2=1550.40 \mathrm{~nm}$ ) for a WDM ch. spacing of $12.5 \mathrm{GHz}$.

The Q-factor of the demultiplexed and demodulated WDM channel at ${ }_{2}=1550.40 \mathrm{~nm}$ is about $13 \mathrm{~dB}$, when the channels at ${ }_{1}=1550.20 \mathrm{~nm}$ and ${ }_{3}=1550.60$ $\mathrm{nm}$ are simultaneously present. This is below $15.6 \mathrm{~dB}$, which corresponds to error free (bit-errorratio better than $10^{-9}$ ) signal demodulation and detection. From Fig 3 , it is observed that, as the neighbouring channels are removed, the system performance in terms of Q-factor improves, as expected and the measured Q-factors are above 15.6 $\mathrm{dB}$. Next, the WDM channel spacing is increased to
$25 \mathrm{GHz}$. In Fig 4, the Q-factor for the 3 demodulated WDM channels is shown for back-to-back measurement and after $25 \mathrm{~km}$ transmission in the case of $25 \mathrm{GHz}$ channel spacing. The measured $\mathrm{Q}$ factors are all above $15.6 \mathrm{~dB}$, which corresponds to error free signal demodulation and detection. We stress that, even though no dispersion compensation algorithm has been used, error free signal demodulation is still obtainable after $25 \mathrm{~km}$.

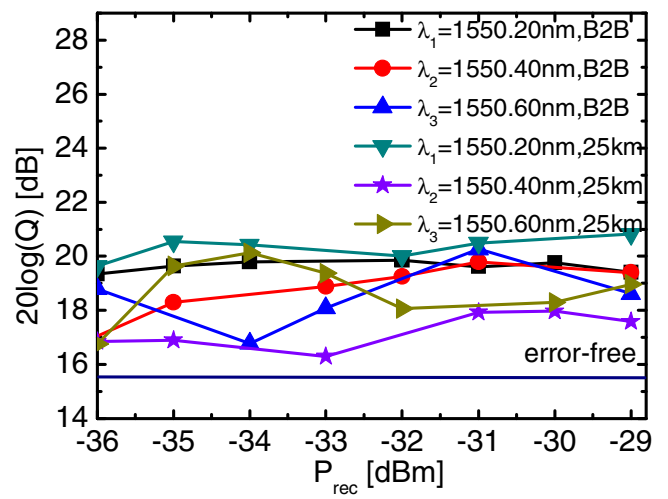

Figure 4. Q-factor of demodulated WDM channels (25 GHz spacing) for back-to-back and after $25 \mathrm{~km}$

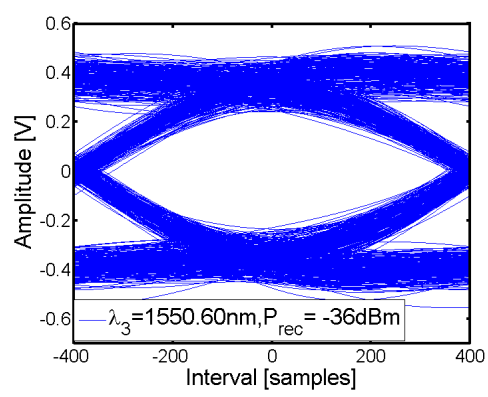

Figure 5. Eye diagram of the demodulated WDM channel

In Fig. 5, an eye diagram of the demultiplexed and demodulated WDM channel $\left({ }_{1}=1550.60 \mathrm{~nm}, \mathrm{P}_{\text {rec }}=\right.$ $36 \mathrm{dBm}$ ) is shown after $25 \mathrm{~km}$ of transmission. A very clean eye diagram is observed confirming error free signal demodulation.

\section{Conclusion}

We have experimentally demonstrated a novel concept of WDM phase-modulated radio-over-fibre link using digital coherent detection. Successful demultiplexing and signal demodulation for WDM channel spacings of $25 \mathrm{GHz}$ has been demonstrated for BPSK modulation of a $5 \mathrm{GHz}$ RF carrier.

\section{References}

1. C. Lim et al., IEEE/OSA J. Lightwave Tech., 21, (2003) pp. 3308-3315

2. T. Nakasyotani et al., IEEE/OSA J. Lightwave Tech., 24, (2006), pp. 404-410

3. H. Chou et al., IEEE PTL, 19, (2007), pp.686-688

4. D. Zibar et al., OFC (2008), OThH3 